Religare, ISSN: 19826605, v.14, n.1, agosto de 2017, p. 109-130.

\title{
Magnetizadoras, sonâmbulas e médiuns: as ousadas brasileiras do século XIX e o caldeirão de práticas que influenciaram o espiritismo
}

\author{
Magnetizers, somnambulists and mediums: the bold \\ nineteenth-century Brazilian women and the cauldron of \\ practices which influenced Spiritism
}

Michelle Veronese ${ }^{1}$

\section{Resumo}

Quando o espiritismo ainda não havia se estabelecido no Brasil, borbulhava em nossas cidades um caldeirão de práticas que incluíam magnetismo, sonambulismo e comunicação com os mortos. Esse caldo adensou quando as ideias e livros de Allan Kardec chegaram por aqui, influenciando os rumos que seu mix de filosofia, ciência e religião seguiria em nossas terras. Neste artigo, produzido com base numa pesquisa em periódicos do século XIX, olho para este cenário e trago à tona as mulheres, especificamente para aquelas que atuaram como sonâmbulas, magnetizadoras e primeiras médiuns. Meu intuito não é apresentar essas personagens apenas como mera curiosidade, embora lançar luz sobre aspectos pouco conhecidos de nosso passado sempre seja válido. Minha intenção principal é apontar os encontros e cruzamentos entre algumas práticas e saberes que ocorreram no contexto urbano de 1850 até fins do século destacando suas influências em nosso campo religioso e, ao mesmo tempo, chamar a atenção para o papel, ainda pouquíssimo estudado, das mulheres na gênese no espiritismo.

Palavras-chave: mulheres; espiritismo; magnetismo; ciência e religião.

${ }^{1}$ Doutora em Ciências Sociais pela Pontifícia Universidade Católica de São Paulo (PUC-SP) e mestre em Ciências da Religião pela mesma instituição. 
Religare, ISSN: 19826605, v.14, n.1, agosto de 2017, p. 109-130.

\begin{abstract}
Before Spiritism had settled in Brazil, it bubbled in our cities a cauldron of practices that included Magnetism, sleepwalking and communication with the dead. This broth thickened when Allan Kardec's ideas and books arrived here, influencing how his mix of philosophy, science and religion would be disseminated here. This article is based on a research in newspapers from the nineteenth-century. It highlights the women who worked as somnambulists, magnetizers and the first mediums. My intention is not to present them as mere curiosity, although shedding light on less known aspects of our past is always valid. My main intention is to point out the crossovers between some practices and pieces of knowledge in the urban context of the 1850s to the end of the century and to stress their influences in our religious field. By doing that, I try to draw attention to the role of women in the genesis of Spiritism, a subject that has been insufficiently researched in Brazil.
\end{abstract}

Keywords: women; Spiritism; Mesmerism; science and religion.

\title{
Introdução
}

O contato do nosso país com a doutrina espírita ocorreu em fins da década de 1850, quando o Livro dos Espíritos chegou por aqui, a bordo de um dos muitos vapores e paquetes que cruzavam o Atlântico e traziam, para deleite da nossa Corte, as notícias, modas e mercadorias de além-mar. A obra inicialmente teria sido lida e debatida em alguns círculos da elite e da intelectualidade, entre eles, o da colônia francesa do Rio de Janeiro. Animados pelos relatos de Allan Kardec sobre o contato com espíritos na França, grupos informais logo começaram a realizar seus próprios experimentos de comunicação com os mortos. Daí em diante, o que parecia um modismo passageiro ganhou contornos de movimento religioso; os grupos foram crescendo, organizando-se, lutando por legitimidade até darem forma a uma das religiões mais populares do país.

Não quero, neste artigo, retomar a trajetória do espiritismo em nossas terras, mas, sim, olhar para os primeiros momentos em que este aportou por aqui, afim de 
Religare, ISSN: 19826605, v.14, n.1, agosto de 2017, p. 109-130.

apresentar elementos e personagens que tendem a passar desapercebidos nos estudos sobre esta religião. Tratarei especificamente das mulheres sonâmbulas, magnetizadoras e primeiras médiuns. Essas personagens, conforme pude apurar na pesquisa que realizei em jornais brasileiros do século $\mathrm{XIX}^{2}$, participaram do início deste movimento no Brasil, seja atuando nas primeiras sessões e grupos espíritas ou engrossando aquilo que chamo de caldeirão mágico-científico-religioso, o qual borbulhou em nossas cidades no século XIX e que também influencio esta religião.

Em locais como Rio de Janeiro, Recife e Salvador, descobri que nossas sonâmbulas e magnetizadoras ofereciam serviços de cura e previsões, realizavam espetáculos teatrais descritos como científicos mas repletos de elementos sobrenaturais e ainda demonstravam suas habilidades nos salões da Corte. Quando o interesse pela comunicação com os mortos ganhou força por aqui, a partir de 1850, despertado pelas notícias sobre o espiritualismo norte-americano e pelas obras de Allan Kardec, essas brasileiras não ficaram de fora. Contatar espíritos logo passou a fazer parte do repertório de muitas delas. Seu papel e influência no espiritismo brasileiro, defendo aqui, podem ser pensandos tanto a partir do caldeirão de práticas e crenças do qual elas tomaram parte quanto das articulações que realizavam entre magnetismo e espiritismo e também entre ciência e religião.

Este artigo está estruturado da seguinte maneira: no primeiro item, mostro como magnetismo começou a se popularizar no Brasil, citando as primeiras sonâmbulas e o frisson que essas mulheres e suas práticas causaram nas cidades do Império; em seguida, trato das magnetizadoras e aponto algumas de suas "subversões". Falo então do encontro do espiritismo com magnetismo e

\footnotetext{
${ }^{2}$ Os periódicos que menciono neste artigo foram selecionados e analisados durante minha pesquisa de doutorado em Ciências Sociais, pela PUC de São Paulo, cujo título é: "De silêncios e resistências - sonâmbulas, magnetizadoras e outras esquecidas do espiritismo brasileiro", defendida em 2017. Essas publicações foram consultadas no Arquivo Histórico de São Paulo, no Arquivo da Federação Espírita do Estado de São Paulo, na Hemeroteca Digital Biblioteca Nacional e na Library of Congress (no caso dos periódicos estrangeiros).
} 
Religare, ISSN: 19826605, v.14, n.1, agosto de 2017, p. 109-130.

sonambulismo e dos cruzamentos e, na quarta parte, analiso o caldeirão que se formou por aqui. Concluo discutindo o que pode ter representado ser sonâmbula, magnetizadora ou médium para as brasileiras do século XIX.

\section{O magnetismo no Brasil e as mulheres que mesmerizaram o Império}

O mesmerismo - ou magnetismo animal - tornou-se conhecido a partir do século XVIII, quando Franz Mesmer³ (1734-1815) apresentou ao mundo suas ideias sobre a existência de uma força invisível e universal chamada fluido magnético e que, segundo ele, perpassava todos os corpos e objetos. Defendia ele que a causa das doenças estava no desequilíbrio deste fluido em nossos corpos, portanto, para tratarmos os mais diversos males, bastaria reequilibrar a circulação do mesmo. Em suas terapias, Mesmer utilizava ímãs e tanques, massagens e toques. Seu método mais comum era a imposição das mãos sobre o indivíduo doente, chamado de passe magnético. Com este gesto, acreditava que uma pessoa poderia transferir um pouco do seu fluido para outra, promovendo a cura de doenças.

Os seguidores de Mesmer, conhecidos como magnetizadores, popularizaram essas práticas, acrescentando novos elementos a elas. Na França e na Inglaterra do século XIX, eles ofereciam terapias de cura em consultórios privados - os chamados gabinetes ou consultórios magnéticos - e realizavam demonstrações públicas ao mesmo tempo em que tentavam convencer as sociedades médicas e científicas da legitimidade de suas ideias. Muitos deles, àquela época, contavam com um tipo peculiar de assistente: um sonâmbulo ou uma sonâmbula. Esses indivíduos eram

\footnotetext{
${ }^{3}$ Franz Anton Mesmer (1734-1815) nasceu na Alemanha, estudou na Áustria e completou seus estudos médicos com uma tese sobre a influência dos planetas nas doenças humanas. Suas proposta de cura por meio do que chamava de "magnetismo animal" o tornaram famoso, levando-o a conquistar admiradores entre artistas e aristocratas. Chegou a abrir um consultório magnético em Paris. Depois de fracassar em provar a eficácia de seus métodos de cura, morreu desacreditado.
} 
Religare, ISSN: 19826605, v.14, n.1, agosto de 2017, p. 109-130.

colocados sob uma espécie de sono hipnótico e, nesse estado, receitavam tratamentos para doenças, faziam previsões e adivinhações.

O Brasil não ficou de fora desse movimento e também teve seus magnetizadores e sonâmbulos - assim como magnetizadoras e sonâmbulas. Encontrei essas duplas em notas, artigos, cartas e anúncios publicados em nossos jornais a partir de 1830. Naquela década, nossa imprensa já falava daquele que, ao que tudo indica, foi o primeiro a colocar em prática por aqui as teorias de Mesmer. Trata-se de José Leopoldo Gamard - ou Doutor Gamard, como o próprio se intitulava. Em seu consultório na Rua do Ouvidor, no Rio de Janeiro, este magnetizador oferecia tratamentos para os mais diversos males: "desordens do útero, cancro no peito, estreitamento, carnosidade na uretra, enxação nos escrotos, ou hidrócelo e sarcocelo... e toda e qualquer (sic) moléstias nervosas". Suas terapias, segundo informava nos anúncios e cartas que publicava na imprensa, não envolviam "operação de cirurgia" e, sim, o "único meio que se emprega em todas as Cortes da Europa, a qual se chama Magnetismo Animal" (DIÁRIO DO RIO DE JANEIRO, 31 DE MARÇO DE 1836).

A exemplo de seus colegas europeus, Gamard também contava com os serviços de uma sonâmbula. Era essa mulher, que ele apresentava como sua assistente, fazia o diagnóstico das doenças dos pacientes. O ideal, dizia, era a pessoa visitar a dupla em seu consultório. Mas, para quem não podia ir pessoalmente, havia a opção de enviar "um lençol que lhe pertença ou um pouco de seus cabelos ou, enfim, um escrito qualquer de seu punho" (JORNAL DO COMMERCIO, 1 de março de 1845 e 29 de junho de 1845). De posso desses itens, a sonâmbula indicaria o melhor tratamento.

Depois de Gamard, vieram outros magnetizadores e sonâmbulas. Nos jornais da época, encontrei diversos relatos de jornalistas que compareceram às sessões e experimentos magnéticos realizadas por esses indivíduos para depois narrar os 
Religare, ISSN: 19826605, v.14, n.1, agosto de 2017, p. 109-130.

detalhes aos leitores e leitoras. Foi o caso da colunista A. ${ }^{4}$, de O Jornal das Senhoras. Em 1854, ela escreveu:

Já que tudo é magnetismo, que por ele se curam todas as enfermidades, desde a gota e demência senil até os males do amor; nesta época em que o famigerado e rendoso magnetismo põe patentes todos os arcanos passados, presentes e futuros, não podíamos nem deveríamos ter a fria indiferença de não consultar nosso destino (O JORNAL DAS SENHORAS, PRIMEIRA EDIÇÃO DE JANEIRO DE 1854).

Na década de 1850, a possibilidade de tratar doenças e vislumbrar o futuro com a ajuda do fluido magnético era um frisson por aqui, conforme contam os jornais da época. "Em todo o lugar onde ouvirdes uma discussão acalorada, quer seja nos salões, no campo, nos boudoirs, nos corredores, nas ruas, e até nas escadas", comentava o Diário do Rio de Janeiro, "ficai certo que se não trata nem das eleições, nem dos macadames, nem dos caminhos de ferro; é o magnetismo". Tal fenômeno, explicava O Jornal das Senhoras, constituía "a ordem do dia, tanto para as senhoras quanto para os homens" e uma moda "autenticada... por célebres e acreditáveis doutores, alemães, portugueses, americanos e franceses (17 de julho de 1853).

Foi nesse cenário, no início dos anos 1850, que uma sonâmbula se destacou entre as demais. Seu nome era Lucrécia e ela se apresentava ao lado do irmão, o magnetizador Jácomo Ulysses, em teatros de norte a sul do pais. Suas apresentações - anunciadas como "cursos de magnetismo animal" e demonstrações de "physica

\footnotetext{
${ }^{4}$ Uma das primeiras folhas administradas e escritas por mulheres, O Jornal das Senhoras deixava claro, desde sua primeira edição, seu posicionamento contra os estereótipos associados às mulheres da época e a favor da emancipação delas. Mesmo assim, preferia ser "um confidente discreto" das brasileiras, sem exigir que suas colaboradoras assinassem os textos que produziam. Algumas identificavam-se com pseudônimos e outras com iniciais, a exemplo da colunista mencionada acima, que escreveu sobre o magnetismo e assinou apenas como A..
} 
Religare, ISSN: 19826605, v.14, n.1, agosto de 2017, p. 109-130.

recreativa" (Diário do Rio de Janeiro, 20 de julho de 1852) - atraíram multidões e lotaram teatros em cidades como Recife, São Luís, Salvador, além do Rio de Janeiro.

Em 20 de julho de 1852, o Diário do Rio de Janeiro trazia detalhes de um desses espetáculos. No palco, Lucrécia “desempenhará a duplicada vista magnética, sendo magnetizada por seu irmão" e "adivinhará tudo o que lhe for perguntado e apresentado pelo magnetizador", ficavam então sabendo os leitores e leitoras. Para garantir a casa lotada - ou talvez para convencer os mais céticos - as notas publicitárias frequentemente informavam que o magnetismo era bastante popular na França, inclusive entre médicos e cientistas. É o que mostra o trecho abaixo, do mesmo jornal:

Os fatos raros que esta admirável ciência ainda tão pouco conhecida tem apresentado excitou em França a mais profunda atenção entre os mais hábeis e distintos professores, a um tal ponto que moveu a escola de medicina a fazer novas análises acerca do magnetismo animal (DIÁRIO DO RIO DE JANEIRO, 20 DE JULHO DE 1852).

Apesar de divulgados como demonstrações de uma nova e "admirável ciência", os espetáculos de magnetismo e sonambulismo eram marcados por uma forte aura de mistério e sobrenatural. De olhos vendados, sonâmbulas como Lucrécia adivinhavam o conteúdo dos bolsos dos clientes, "projetavam sua visão" para países distantes, faziam diagnósticos de doenças e previsões de futuro. “Mr. Jacome fecha um objeto na mão, por exemplo um relógio e pergunta o que lhe mandam perguntar, e ela vai respondendo até o número do relógio, o autor, a fábrica", narrou o jornal O Cearense em 1 de setembro de 1857. E foi exatamente por isso que essas personagens incomodaram representantes tanto do campo da ciência quanto da religião, como veremos a seguir.

\section{As magnetizadoras e suas subversões}


Religare, ISSN: 19826605, v.14, n.1, agosto de 2017, p. 109-130.

Enquanto Lucrécia conciliava espetáculos públicos com atendimentos privados, as sonâmbulas brasileiras, em geral, mantiveram-se longe dos holofotes. Embora muito se falasse sobre a presença delas em nossas cidades, suas histórias de vida e detalhes de suas trajetórias não são mencionados em nenhum momento. Onde nasceram, como viviam, a que classe social pertenciam, como se envolveram com o magnetismo e como percebiam sua experiência são algumas das muitas questões que permanecem em aberto a respeito dessas mulheres.

Podemos pensar a ausência de registros sobre essas personagens com Michelle Perrot (2005), que chamou a atenção para os silêncios, lacunas e apagamentos de grupos marginais. “Os escrivães da história”, observou, "tomam nota de muito pouco do que tem o traço das mulheres" (PERROT, 2005, p. 33). Quando o silêncio é quebrado, geralmente é para apontar comportamentos excepcionais: "As que aparecem no relato dos cronistas são quase sempre excepcionais por sua beleza, virtude, heroísmo ou, pelo contrário, por suas intervenções tenebrosas e nocivas, suas vidas escandalosas", escreve Perrot (1995, p. 13). Isso vai prosseguir até o século XIX.

Outro aspecto que chamou minha atenção ao pesquisar essas personagens é que havia inicialmente, no Brasil, uma clara divisão de papeis nos consultórios magnéticos: os homens eram magnetizadores, as mulheres atuavam como sonâmbulas. John Warne Monroe, ao estudar o mesmerismo ${ }^{5}$ na França dos séculos XVIII e XIX, também observou uma separação de funções naquele contexto. Os estereótipos de gênero da época serviam para justificar tal diferenciação. Os magnetizadores, por exemplo, como notou Mornoe, eram descritos por sua "vitalidade física - geralmente vista como reflexo da quantidade de fluido magnético que controlavam - sua assertividade, sua força de vontade prodigiosa e

\footnotetext{
${ }^{5}$ Alguns autores preferem utilizar o termo "mesmerismo" em vez de "magnetismo animal", afim de associar essas práticas e saberes a Mesmer.
} 
Religare, ISSN: 19826605, v.14, n.1, agosto de 2017, p. 109-130.

seu ar de completo domínio sobre o que faziam" (MONROE, 2007, p. 69, trad. livre minha). Já as mulheres, dizia-se, seriam mais aptas a atuaram como sonâmbulas por sua sensibilidade, fragilidade e suposta facilidade de serem colocadas sob o sono magnético.

Essas separação de funções com base em construções de gênero, conforme pude perceber, foi quebrada no Brasil pelas próprias mulheres a partir do momento em que algumas delas começam a atuar também como magnetizadoras. Entre essas personagens, para citar algumas, estão Theresa Meraldi, que se apresentava como "grande adivinha, professora de várias ciências, sonâmbula, magnetizadora pelos estudos do dr. Mesmer, fundador do magnetismo, e a maior cartomante deste século"; Mademoiselle Rosina Ferière, "sonâmbula pelo efeito do pó e da eletricidade, magnetizadora e a maior cartomante da época"; e Adela Mirol, "presidente da escola de magnetismo de Paris" e "membro honorário da academia de ciências de Roma".

Notemos, nestes anúncios, elas se referem a si com superlativos, afirmandose grandes, fortes, poderosas e respeitadas. Mais do que mera estratégia publicitária, a escolha desses termos revela uma rejeição aos estereótipos associados às mulheres do século XIX, então consideradas criaturas frágeis, sensíveis, modestas e delicadas e das quais eram esperados comportamentos condizentes com essas ideias. Outro detalhe não menos importante é que essas personagens, a partir do momento em que assumem o papel de magnetizadoras, deixam de lado o anonimato. O público toma, então, finalmente conhecimento de seus nomes - ainda que talvez alguns sejam pseudônimos - e elas, por sua vez, tomam para si o domínio de um conjunto de saberes até então exclusivo dos homens.

Essas não foram as únicas subversões ${ }^{6}$ realizadas por essas mulheres.

${ }^{6}$ Utilizo "subversão" no sentido de abalo a estruturas, relações e sistemas estabelecidos. 
Religare, ISSN: 19826605, v.14, n.1, agosto de 2017, p. 109-130.

A fama e a popularidade de muitas delas despertou a ira de alguns setores da sociedade, especialmente médicos e religiosos, que passaram a condenar publicamente suas práticas. Os primeiros as acusavam de charlatanismo e de exercício ilegal da Medicina; já a Igreja Católica as via como hereges, feiticeiras e aliadas do demônio. Alguns jornais também tomaram partido, colocando-se, pela voz de seus articulistas, contra o magnetismo e o sonambulismo e frequentemente denegrindo tais mulheres.

O Liberal Pernambucano, em um artigo intitulado Sonambulismo, dizia que "indivíduos suscetíveis e fracos" não deveriam se consultar com as sonâmbulas. Eis um trecho do texto, no qual uma dessa mulheres é chamada de "sybilla" (sibila, na grafia atual), uma referência, em tom pejorativo, a mulheres da Grécia e Roma Antigas a quem se atribuía do dom da profecia:

Não nos recordamos como se chamava a sublime sybilla que íamos ouvir discorrer; mas uma voz magnetizada, e pouco tempo levou, foi interrogada pelo magnetizador. [...] a rapariga fazia contorções estudadas, movimentos de quem estava muito bem acordada [...] Se isto é sonambulismo, e cremos que não há outro, deixa muito a desejar e é digno de ser tomado em consideração por poder ser prejudicialíssimo a indivíduos suscetíveis e fracos (LIBERAL PERNAMBUCANO, DE 3 DE MARÇO DE 1854).

As críticas a quem praticava magnetismo e sonambulismo se acentuaram a partir de 1860, quando as ideias higienistas eram colocadas em prática por aqui. Conforme as cidades cresciam e viam sua população se multiplicar, buscava-se higienizá-las não apenas por meio de saneamento e de políticas de limpeza pública, mas também "limpando-as" de barbeiros, homeopatas, curandeiros, magnetizadores, sonâmbulas e espíritas.

Em 1862, o médico Nicolau Joaquim Moreira fez um pronunciamento sobre estas questões na Imperial Academia de Medicina do Rio de Janeiro. Diante do Imperador e de seus colegas, ele apresentou suas "considerações sobre o 
Religare, ISSN: 19826605, v.14, n.1, agosto de 2017, p. 109-130.

maravilhoso, o charlatanismo e o exercício ilegal da medicina e da pharmacia". Ao se referir às mulheres, também as associa às "sybillas", e considera essas práticas "maravilhas que ofuscam a razão", crenças "mysticas" que haviam se transformado em "meio terapêutico". Eis um trecho de seu discurso, publicado nos Anais de Medicina daquele ano:

Os adeptos do sonambulismo vão muito além: emprestam a seus magnetizados os dons da previsão e da ubiquidade, atributos pertencentes ao Criador, e o conhecimento de todas as ciências. Declarando sonâmbulos os profetas e sybillas da antiguidade e magnetizadores os apóstolos e o mesmo Filho de Deus, desprezando as condições de tempo e espaço, dizem curar febres as 10 léguas de distancia, paralisia em hora e meia e procurando transformar o sonambulismo em meio terapêutico, apenas alcançam fazer dele um novo meio de subsistência (ANAIS DE MEDICINA, 1862, P. 68)

A visão de Moreira era a visão geral de muitos médicos, religiosos e de todos aqueles incomodados com a popularidade das magnetizadoras, magnetizadores e sonâmbulas em nosso país. Essas personagens haviam ousado entrar em dois campos que não eram de seu domínio, o da religião, a partir do momento em que flertavam com o sobrenatural (ou, como diz o trecho acima, quando tomaram emprestados "atributos do Criador"), e o da ciência, pelo fato de terem utilizado suas práticas como meio terapêutico (fazendo delas "um novo meio de subsistência", nas palavras acima).

\section{Os espiritos entram em cena e o caldeirão ferve}

Na época em que o magnetismo vivia um boom em nosso país, os jornais também passaram a tratar dos fenômenos das "mesas e chapéus girantes" ou “batidas espirituais". Esses haviam começado em 1848, nos Estados Unidos, quando as irmãs Fox afirmaram ter se comunicado com o espírito de uma pessoa morta. Tal contato teria ocorrido, diziam as meninas, por meio de pancadas nas paredes de sua 
Religare, ISSN: 19826605, v.14, n.1, agosto de 2017, p. 109-130.

casa. As sons, segundo elas, eram excetuados pela entidade e cada um representava um número ou letra. Traduzidas, as batidas revelavam mensagens que, acreditavase, vinham do Além. Esses fenômenos, que pareciam restritos à pacata cidade de Hydesville, repercutiram mundo afora graças à cobertura da imprensa e ao ritmo do telégrafo, que havia acelerado a comunicação à longa distância. Em pouco tempo, pipocaram relatos de outra pessoas que diziam se comunicar com espíritos ${ }^{7}$, seja por meio de batidas nas paredes ou de objetos que se moviam, como mesas e chapéus. ${ }^{8}$

A partir daí, surgiu a figura do médium - indivíduo que, como sugere o número, servia de canal para espíritos se manifestarem. Grupos começaram a se organizar em torno desses personagens, conferências foram realizadas e a imprensa internacional repercutia cada vez mais o assunto (ELLWOOD e ALLES, 2007, p. 429). O Spiritual Telegraph, um dos primeiros jornais a se dedicar exclusivamente à cobertura da comunicação com os mortos, escreveu em 1854: "Raramente se passa um dia em que não chegue até nós um novo e impressionante exemplo da presença e do poder espiritual entre os homens".

Quando as mesas e chapéus girantes encontraram-se com as sonâmbulas, magnetizadoras e magnetizadores, o interesse por essas práticas aumentou ainda mais. A partir daí, conforme narram os jornais, aumentou o número de pessoas que não só recorriam aos tratamentos magnéticos, mas que começavam a realizar, em casa ou nos salões da corte, de modo bastante informal, seus próprios experimentos.

\footnotetext{
${ }^{7}$ A semelhança entre as chamadas "pancadas espirituais" e o telégrafo, uma das grandes novidades da época, responsável por acelerar a comunicação à longa distância, é um tanto curiosa: em ambos os casos, as batidas eram traduzidas em letras que, ao final, revelavam mensagens vindas de longe. Não por acaso, os primeiros indivíduos que intermediavam a comunicação com os mortos eram chamados de "telégrafos espirituais". E um dos primeiros periódicos criados para divulgar o então nascente movimento espiritualista, que surgiu a partir destes fenômenos, chamava-se Spiritual Telegraph.

${ }^{8}$ Relatos sobre os fenômenos de Hydesville podem ser encontrados em vários artigos e livros publicados ainda no século XIX. Em 1890, por exemplo, o jornal The Salt Lake Herald, p. 13, traz uma reportagem sobre o início do movimento espiritualista. O título é: "How it Originated. Hydesville, the Birthplace of Modern Spiritualism" (Como se originou. Hydesville, o local de nascimento do Espiritualismo Moderno).
} 
Religare, ISSN: 19826605, v.14, n.1, agosto de 2017, p. 109-130.

“O Rio de Janeiro está também neste momento sob a influência do magnetismo. Por toda a parte se fazem experiências", escrevia, em 23 de julho de 1853, o jornal Marmota Fluminense em um artigo intitulado A Dança das Mesas. Naquela edição, para saciar a curiosidade do público, o periódico ensinava aos leitores e leitoras como fazer o tamborete (mocho) do piano se mover. "O mocho do piano, como todo o mundo sabe, tem um parafuso, que o faz subir e descer; pois bem, duas ou três pessoas bastam para que ele gire pela influência do magnetismo!", lia-se no passo a passo.

Ninguém sabia ao certo, no Brasil, a causa daqueles fenômenos - diziam alguns que era o magnetismo que fazia objetos como o mocho do piano se moverem; outros insistiam que eram espíritos que estavam por trás daqueles movimentos. $\mathrm{O}$ fato é que o caldeirão de práticas, serviços e entretenimentos disponibilizado aos moradores de nossas cidades começava a borbulhar ainda mais. E o caldo adensou quando O Livro dos Espíritos, de Allan Kardec, passou a circular por aqui.

Conforme as ideias do chamado codificador do espiritismo iam sendo estudadas e debatidas, inspirando experimentos de comunicação com os mortos, novos elementos também eram adicionados àquele mix. Nos consultórios de magnetismo, nos salões da Corte e em encontros de grupos informais, era possível tanto fazer mesas, chapéus e bancos dançarem quanto receber mensagens espirituais, vislumbrar o futuro ou curar as moléstias do corpo.

Todas essas possibilidades foram experimentadas, misturadas, interpretadas e explicadas ao gosto daqueles que por elas se interessavam. Os textos publicados na imprensa da época ilustram muito bem esse intercâmbio de práticas e ideias que se influenciavam mutuamente. Nos artigos, anúncios, notas e crônicas que trataram destas novidades, é interessante notar, nem sempre está claro o que é magnetismo e espiritismo ou espiritualismo - esses termos, àquele tempo, foram muitas vezes 
Religare, ISSN: 19826605, v.14, n.1, agosto de 2017, p. 109-130.

empregados como sinônimos, o que deve ser visto menos como descuido de jornalistas e mais como um reflexo dos cruzamentos que então ocorriam.

Nas páginas dos classificados, espaços em que as sonâmbulas e magnetizadoras divulgavam seus serviços, essa dinâmica fica mais evidente. Adela Mirol, por exemplo, dizia-se dona de um “Consultório de Magnetismo, Espiritismo e Cartomancia". E, além de médium, apresentava-se como "célebre sonâmbula e professora de magnetismo e outras ciências ocultas". Este um entre muitos exemplos que a leitura dos periódicos antigos revela.

Conforme os grupos espíritas vão surgindo e se organizando, mulheres que atuavam como sonâmbulas também estarão presentes neles, então como médiunssonâmbulas. Daquelas primeiras a se ligarem ao espiritismo, entretanto, há esparsos registros. Sabemos de sua existência - quando ficamos sabendo - pelas iniciais de seus nomes ou quando os jornais citam uma "certa senhora", "madame" ou "mademoiselle" que atuavam como médium, sonâmbula ou receitista. No primeiro periódico espírita brasileiro, o Écho D'Alêm-Tumulo, por exemplo, temos a "médium Dona E.", que, no ano de 1867, recebia mensagens de Santo Agostinho, em estado de "sonambulismo espontâneo" (O ÉCHO D'ALÊM-TUMULO, 1869, p. 40). Noutra edição do mesmo jornal, mais uma médium aparece: Mme. Vve. P. C., sobre a qual o jornal informava apenas que era uma "respeitável senhora".

As referências às primeiras brasileiras que atuaram como médiunssonâmbulas, seja transmitindo mensagens espirituais ou prescrevendo receitas e tratamentos de saúde, seguem fragmentadas. O silêncio vai sendo quebrado apenas aos poucos, conforme nos aproximamos do fim do século. Em 1900, para citar um exemplo, o jornal espírita Verdade e Luz menciona Dona Sophia, moradora de São Roque (SP). Ela, diz o periódico, teria curado o pai de uma doença que atingiu a perna dele. O tratamento incluiu "lavagens de cozimento de folhas de laranjeiras" e 
Religare, ISSN: 19826605, v.14, n.1, agosto de 2017, p. 109-130.

havia sido prescrito "por conselho do espírito de João Franciscano". Mais nada é dito sobre ela.

Esconder as identidades dessas mulheres pode ter sido uma estratégia, tanto delas quanto dos grupos dos quais participavam, para evitar críticas e perseguições em uma época em que cresciam as tensões entre espíritas e a Igreja Católica. Mas, e não podemos deixar de considerar isto, também é reflexo das relações de poder de uma sociedade que tendeu a excluir a participação feminina das mais diversas áreas. Naquele tempo, vale lembrar, estava bastante claro o que se esperava das brasileiras (as das classes mais abastadas). Elas deveriam ser mães devotadas, esposas submissas e católicas tementes. Os ideias da família burguesa se resumiam - e resumiam as mulheres - a, como nota D'Incao: “Um sólido ambiente familiar, o lar acolhedor, filhos educados e esposa dedicada ao marido, às crianças e desobrigada de qualquer trabalho produtivo" (D'INCAO, 1997, p. 223).

Já no século XX, é por meio das biografias oficiais de personagens do espiritismo que ficamos sabendo daquelas que primeiro se interessaram por essa doutrina. Mas aí surgem dois problemas: tratam-se de leituras desta religião sobre aquela época e sobre as mulheres; e deixou-se de fora justamente o período anterior à unificação dos grupos, à sistematização das práticas e à criação da FEB (Federação Espírita Brasileira). A participação das brasileiras no espiritismo, assim, é contada somente a partir de personagens como Aura Celeste, Anália Franco e outras elencadas entre os "grandes vultos" desta religião. ${ }^{9}$ Resultado: ao lermos essas obras e todos aqueles trabalhos que nelas se basearam, não ficamos sabendo daqueles anos em que as sonâmbulas, magnetizadoras e primeiras médiuns atuaram e partilharam saberes e práticas, oferecendo serviços de terapias, curas, previsões e contatos com

\footnotetext{
${ }^{9}$ É o que se nota em títulos como: Grandes Espíritas do Brasil (1969), de Zeus Wantuil, publicado pela FEB (Federação Espírita Brasileira); Os Grandes Vultos do Espiritismo (1981), de Paulo Alves Godoy, também publicado pela editora da FEB; Personagens do Espiritismo - do Brasil e de Outras Terras (1982), de Antônio de Souza Lucena e Paulo Alves Godoy, publicado pela editora da FEESP (Federação Espírita do Estado de São Paulo).
} 
Religare, ISSN: 19826605, v.14, n.1, agosto de 2017, p. 109-130.

os espíritos em nossa cidades, onde tornaram-se figuras populares e polêmicas. Essas primeiras mulheres que se relacionaram com o espiritismo que então nascia ficaram de fora dos registros - foram ocultadas, esquecidas.

As influências destas personagens, no entanto, ainda ecoam nos dias de hoje e podem ser percebidas, de modo mais evidente, nas águas fluidificadas, nos passes magnéticos e nas receitas prescritas por médiuns em centros espíritas. Essas, lembremos, eram práticas que faziam parte do repertório das sonâmbulas e magnetizadoras antes mesmo que se falasse de Kardec por aqui.

\section{Nas fronteiras entre ciência e religião}

Magnetismo, mesas girantes e espiritismo não eram as únicas opções ofertadas àqueles que buscavam novos entretenimentos, cura ou consolo no contexto das cidades do século XIX. Na análise dos jornais daquele período, percebi um caldeirão de crenças e práticas que incluíam também homeopatas, mágicos, cartomantes, videntes, pílulas para afinar o sangue, unguentos que curavam, ervas miraculosas... Frequentemente, ao abrir as páginas dos classificados e ao depararme com aquela variedade de serviços e propostas, lembrei-me do que se costumou

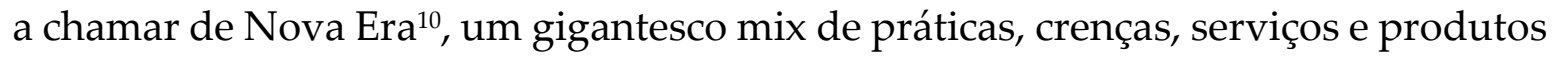
que, a partir dos anos 1960, passaram a ser ofertados na cidade.

As terapias alternativas de cura, a crença em forças invisíveis que qualquer indivíduo treinado poderia contatar, a roupagem mágica e sobrenatural dada a

\footnotetext{
${ }^{10}$ Uso o termo "nova era" sabendo que este é insuficiente para abarcar o fenômeno que, com ele, tentou-se definir. Como lembra Silas Guerriero (2003), esta não se trata de uma Igreja, movimento religioso ou grupo com fronteiras limitadas. É na verdade um termo - e não o único - utilizado para designar um fenômeno que se intensificou nas sociedades ocidentais a partir dos 1960, marcado pela emergência e a popularidade de crenças, práticas, serviços e produtos que incluíam de terapias alternativas a novas formas de se relacionar como o Sagrado. Xamanismo, Wicca, Druidismo, tarot, ocultismo, feng-shui, yoga, meditação transcendental e a crença em extraterrestres, gnomos e duendes são algumas das muitas expressões abarcadas neste guarda-chuva.
} 
Religare, ISSN: 19826605, v.14, n.1, agosto de 2017, p. 109-130.

ideias científicas, as fronteiras borradas entre ciência e religião - muito daquilo que observamos na contemporaneidade e abarcamos sob termos como nova era, novas religiosidades, novas espiritualidades, novos movimentos religiosos ou novas expressões do sagrado já fervilhava em nossas cidades na década de 1850, em grau menor. Guardadas as devidas distâncias de tempo e contexto, aquilo que hoje chamamos de novo não é exatamente uma novidade em nossa cidades.

Podemos pensar este caldeirão a partir de duas ideias que, por sinal, foram gestadas no século XIX: secularização e desencantamento. Apresentada por Max Weber, defendida por autores como Peter Berger e Bryan Wilson, criticada e constantemente debatida, a secularização pode ser compreendida como um processo que afetou as sociedades ocidentais que sofreram os efeitos da modernização e da industrialização, o que teria implicado na perda de poder da religião. No cerne da secularização, argumenta Bryan Wilson, há três aspectos principais: o poder político ou militar deixaram de depender da sanção religiosa, o que levou a um mudança no locus de autoridade nas sociedades; a ciência, e não mais a religião, passou a oferecer explicações para os fenômenos do mundo, o que levou a uma mudança na natureza do conhecimento; e, na organização do trabalho, passou-se a exigir comportamentos pautados pela razão e não por "metas sobrenaturais" (WILSON, 1998, p. 50-51).

$\mathrm{Na}$ visão weberiana, a secularização está intrinsicamente ligada à modernidade e insere-se em um processo histórico-religioso que teria se iniciado muito antes, o qual ele chamou de desencantamento do mundo. Weber, em Ensaios de Sociologia (1982, p. 182), escreveu que o "destino de nossos tempos é caracterizado pela racionalização e intelectualização e, acima de tudo, pelo 'desencantamento do mundo". Mas o que ele quer dizer com esta expressão?

Isso significa que o mundo foi desencantado. Já não precisamos recorrer aos meios mágicos para dominar ou implorar aos espíritos, como fazia o selvagem, para quem esses poderes misteriosos 
Religare, ISSN: 19826605, v.14, n.1, agosto de 2017, p. 109-130.

existiam. Os meios técnicos e os cálculos realizam o serviço. Isto, acima de tudo, é o que significa a intelectualização (WEBER, 1982, p. 165).

A tese da secularização e a ideia de desencantamento do mundo foram bastante criticadas a partir dos anos 1960, justamente quando houve a explosão de novas religiosidades e pelo crescimento dos fundamentalismos religiosos. Em vez de fim da religião, passou-se então a se falar em revanche do sagrado, dessecularização, revival religioso e reencantamento do mundo, entre outros termos.

Ao olhar para o Brasil do século XIX, tendo como base as notas, crônicas, artigos e anúncios publicados em jornais da época, percebo que aqui, embora a sociedade vivesse grandes transformações, com a religião a caminho de separar oficialmente, ao menos - do Estado, o desencantamento, entendido nos termos de Weber, estava longe de acontecer. Na verdade, conforme a ciência avançava e novas invenções e engenhocas transformavam as relações sociais, seguíamos tão ou mais encantados do que antes.

A ideia de secularização sem desencantamento não é minha e foi defendida, entre outros, por Lísias Negrão (2005). Em Nem jardim encantado, nem clube dos intelectuais desencantados, ele explica que "houve, no Brasil, uma persistência do encantamento" (2005, p. 33) ou, como esclarece mais adiante, um "semiencantamento e uma secularização relativa" (p. 35). Para Negrão, deu-se um descompasso entre secularização e encantamento no Brasil. Silas Guerriero, ao estudar a diversidade religiosa na contemporaneidade, também defendeu que não houve um desencantamento no Brasil e, consequentemente, não poderia ter havido um reencantamento como alguns autores propõem, afirmando que:

Não houve desencantamento pois não chegou a termo a racionalização dos objetos sacrais por parte da própria religião. Por outro lado, o crente também nunca se desencantou. Continua vivendo num mundo encantado. A Nova Era é apenas mais uma possibilidade de vivência desse mundo encantado, carregado de 
Religare, ISSN: 19826605, v.14, n.1, agosto de 2017, p. 109-130.

forças invisíveis (chamadas de energias) e de manipulações mágicas (GUERRIERO, 2003, p. 136).

Os exemplos que apresentei neste artigo ilustram um outro ponto que percebi ao observar o século XIX por meio dos jornais que circularam em nossas principais cidades: em vez de varrer crenças e superstições, como tanto se anunciava naquela época, o conhecimento científico acabou desencadeando justamente o oposto, ou seja, muitas vezes serviu de tempero e ingrediente para as práticas e crenças que fervilhavam por aqui. Isso se vê, por exemplo, nos jargões científicos utilizados para divulgar os espetáculos de magnetismo e sonambulismo, anunciados como demonstrações de "physica recreativa", "química industrial" e de uma "nova ciência"; nas defesas apresentadas pelo adeptos do magnetismo, que diziam demonstrar os usos da "força elétrica aplicada"; e na curiosa coincidência (ou não?) envolvendo as batidas espirituais, que começaram a ser ouvidas justamente quando os Estados Unidos aumentaram suas linhas de telégrafos (como vimos anteriormente, os primeiros médiuns foram chamados de "telégrafos espirituais"). As invenções tecnológicas, as descobertas científicas e as transformações

vivenciadas naquela época estão também presentes nesse caldeirão, ora influenciando, ora sendo utilizadas para legitimar as novas propostas de crenças e saberes que dele emergiram.

\section{Conclusão}

Finalizo com uma questão essencial: o que pode ter significado, para as mulheres, atuar nesse contexto de desenvolvimento tecnológico, urbanização e modernização e, ao mesmo tempo, estarem ligadas - mexendo e engrossando um caldo de práticas em que as fronteiras entre ciência e religião, mais do que borradas, muitas vezes sequer estavam estabelecidas? 
Religare, ISSN: 19826605, v.14, n.1, agosto de 2017, p. 109-130.

Relembremos que, durante muito tempo, as brasileiras das classes mais abastadas estiveram submetidas à rígida autoridade de pais, padres e maridos. Com a industrialização e a urbanização, não ocorreu uma imediata libertação para elas. Esse período levou a novas configurações familiares e sociais em que as mulheres ficaram cada vez mais restritas aos espaços da família e do lar ${ }^{11}$. Trabalhar como sonâmbula e magnetizadora, deste modo, não era simplesmente exercer um novo e curioso ofício. Significava obter autonomia e independência e ocupar - aliás, abrir, conquistar - novos espaços numa sociedade que se esforçava para manter as mulheres restritas às esferas do lar e da Igreja. Era também um caminho, ainda que alternativo, para aquelas que sonhavam em ingressar no campo da ciência, ao qual também não tinham acesso. ${ }^{12}$

No campo da religião, atuar como magnetizadora, sonâmbula ou médium significava servir de intermediária entre o mundo dos vivos e mortos, algo que a religião dominante, o catolicismo, não viu com bons olhos. Isso permitiu que as mulheres - e aqui podemos pensar com Bourdieu - abandonassem o papel de estranhas "ao sagrado e ao corpo de administradores do sagrado" para ocuparem uma posição de manipuladoras legítimas desse (BOURDIEU, 2007, p. 43).

Deste modo, a contribuição dessas mulheres vai muito além do espiritismo: está nos abalos que causaram nas relações de poder e gênero do século XIX, nas novas maneiras que encontraram de se relacionar com o Sagrado e nos modos como articularam ciência e religião. Não por acaso, as sonâmbulas, magnetizadoras e primeiras médiuns foram tão criticadas e condenadas, e depois esquecidas.

\footnotetext{
${ }^{11}$ Foi nessa época, para justificar tal separação, que ganhou força a ideia da complementaridade sexual. "A mulher privada, doméstica, emergiu como um contraste ao homem público, racional", nota Londa Schiebinger (2001, p. 142).

${ }^{12}$ Qualquer indivíduo, homem ou mulher, interessado em aprender sobre o magnetismo tinha permissão para isso, sem a necessidade de uma instrução formal. E o próprio Doutor Gamard, no Brasil, chegava a oferecer esse tipo de treinamento às mulheres e mães que desejassem "magnetizar seus pequenos", afim de tratar doenças que afligiam as crianças.
} 
Religare, ISSN: 19826605, v.14, n.1, agosto de 2017, p. 109-130.

\section{Referências}

AUBRÉE, Marion e LAPLANTINE, François. A mesa, o livro e os espíritos: Gênese, evolução e atualidade do movimento social espírita entre França e Brasil. Maceió: Edufal, 2009.

BERGER, Peter. O Dossel Sagrado: elementos para uma teoria sociológica da religião. São Paulo: Edições Paulinas, 1985.

. The Desecularization of the world: a global overview. In: BERGER, Peter

(Org.). The Desecularization of The World. Washington: Ethics and Public Policy Center, 1999.

BOURDIEU, Pierre. A Economia das trocas simbólicas. São Paulo: Perspectiva, 2007.

CAMARGO, Cândido Procópio Ferreira de. Kardecismo e Umbanda: uma interpretação sociológica. São Paulo: Livraria Pioneira Editora, 1961.

D'INCAO, Maria Ângela. Mulher e família burguesa. In: DEL PRIORE, Mary

(Org.). História das Mulheres no Brasil. São Paulo: Contexto, 1997.

DOYLE, Connan. The History of Spiritualism. New York: Cassel and Company, 1926. Disponível em: http://archive.org Acesso em: 13 de julho de 2015.

GUERRIERO, Silas. A Diversidade Religiosa no Brasil: A Nebulosa do Esoterismo e da Nova Era 2003. In: Revista Eletrônica Correlatio, n. 3, abril de 2003.

HOBSBAWM, Eric e RANGER, Terence (orgs.). A invenção das tradições. Rio de Janeiro: Paz e Terra, 1984 .

KARDEC, Allan. O Livro dos Espíritos. Rio de Janeiro: FEB, 1994.

MONROE, John Warne. Laboratories of Faith, Mesmerism, Spiritism and

Occultism in Modern France. Itaca \& London: Cornell University Press, 2008.

NEGRÃO, Lísias. Nem jardim encantado, nem clube dos intelectuais desencantados. In: Revista Brasileira de Ciências Sociais, vol.20, n. 59, São Paulo, outubro de 2005.

PERROT, Michelle. As Mulheres ou os Silêncios da História. Bauru: Edusc, 2005.

. Escrever uma história das mulheres: relato de uma experiência. In:

Cadernos Pagu, n. 4, 1995.

SCHIEBINGER, Londa. O feminismo mudou a ciência? Bauru: Edusc, 2001.

VERONESE, Michelle. De silêncios e resistências: sonâmbulas, magnetizadoras e outras esquecidas do espiritismo brasileiro. Tese de doutorado. Pontifícia

Universidade Católica de São Paulo, 2017, 263 p.

WEBER, Max. Ensaios de Sociologia. Rio de Janeiro: LTC, 1982.

WILSON, Bryan. The Secularization Theory: Criticism and Rebuttals. In:

LAERMANS, Rudy e WILSON, Bryan (Org.). Secularization and Social Integration: 
Religare, ISSN: 19826605, v.14, n.1, agosto de 2017, p. 109-130.

Papers in Honor of Karel Dobbelaere. Leuven, Belgium: Leuven University Press, 1998. 